\title{
개발도상국 개발을 위한 해외 이주 노동자 송금(remittance)
}

맹 준 호 (한국수출입은행 경협기획실 책임연구원)

\section{목 차}

1. 들어가며

2. 해외 이주 노동자 송금의 중요성

3. 해외 이주 노동자 송금의 효과

4. 개발을 위한 해외 이주 노동자 송금의 역할

5. 소결

\section{1. 들어가며}

선진국과 개도국간 임금격차로 인한 소득불균형은 오랫동안 해외 노동이주의 주요한 결정 요인 중 하나로 인식되어 왔으며, 개발에 있어 해외이주 및 송금의 효과는 오랜 기간에 걸쳐 다양하게 평가되어 왔다. 해외 노동이주는 이주민 개인의 삶에 지대한 영향을 줄뿐만 아니라 이주민이 떠나온 공동체와 남겨진 가족들의 삶에도 커다란 영향을 미쳐 왔는데, 해외 이주 노 동자가 겪게 되는 이주과정은 그 효과를 측정하기에 다차원적인 측면이 있어 노동이주의 개발 효과를 측정하는 부분에 있어서도 결과적으로 긍정적인 측면과 부정적인 측면이 모두 발생하 는 것으로 알려져 있다. 이 가운데 이주 노동자의 송금(remittance)은 최근 들어 그 중요성이 더욱 부각되고 있으며, 이러한 송금은 이주 노동자와 이주민이 떠나온 사회를 연결해주는 하 나의 매개체로써의 역할을 하고 있다 (Adams, 2005a).

2003년에 발간된 'Global Development Finance' 연차보고서는 이주 노동자의 송금을 외부 
개발재원의 하나로 인식시키는 계기가 되었으며, 최근에 발간된 다양한 보고서들은 이주 노동 자의 해외송금액이 개도국으로 유입되는 공적개발원조(ODA) 보다 훨씬 큰 규모로 성장하고 있음을 보여준다. 소득그룹별로 보면 중저소득국의 경우, 해외 이주 노동자들이 보내는 송금 액의 총규모가 가장 큰 것으로 나타나고 있으나, 저소득국에서는 해외에서 유입되는 자금흐름 중 가장 비중이 큰 것으로 집계되고 있다 (Adams et al., 2005). 개발의 관점에 있어서도 해 외 이주 노동자 송금은 일반적으로 민간자본의 유입 보다 더 안정적인 것으로 평가되고 있으 며, 그 경제적 효과에 있어서도 상대적으로 소멸성(휘발성)이 낮은 것으로 여겨지고 있다 (Buch et al., 2002).

최근 개발협력 정책에 있어서 국제사회의 논의가 개발도상국의 빈곤퇴치를 위한 협력으로 귀결되고 있는 가운데, 양자 및 다자 공여기관들은 많은 개도국에서 해외 이주 노동자들의 송 금이 중요한 역할을 수행할 뿐만 아니라 빈곤층에 속해 있는 개인과 가정, 그리고 공동체의 생 존을 위한 주요한 재원이라는데 인식을 같이하고 있다 (World Bank, 2006). 왜냐하면 개도국 으로 유입되는 해외 이주 노동자 송금은 지역사회의 생산활동을 장려하고 투자를 촉진하여 지 역개발을 할 수 있는 잠재력을 가지고 있기 때문이다.

본고에서는 이러한 잠재력을 가지고 있는 해외 이주 노동자 송금이 개발 측면에서 가지고 있는 몇 가지 중요한 이슈들을 개괄적으로 짚어보고자 한다. 이어지는 글에서는 먼저 해외 이 주 노동자 송금에 대한 정의와 이주 노동자 송금이 최근 개발 논의에 있어 왜 중요한 이슈로 등장하게 되었는지를 간단히 살펴보고, 계속해서 이주 노동자 송금의 개발효과에 대한 논의를 이어가도록 하겠다.

\section{2. 해외 이주 노동자 송금의 중요성}

해외 이주자가 본국에 보내는 송금은 그 형태에 있어 몇 가지 분류가 있을 수 있지만, 일반 적으로 remittance는 이주자의 해외 소득에서 본국으로 보내지는 화폐의 이체금액을 의미한 다 (Ratha, 2004). 대부분의 관련 논문에서는 해외 이주자 송금의 의미를 더 좁은 의미로 해 석하여 해외 이주자(migrant) 중에서도 이주 노동자(migrant worker)가 본국으로 송금하는 화폐 이체액만을 의미하는 경우가 많으며 1$)$, 난민이나 해외 불법체류자들의 송금액까지도 논

1) 본고에서는 좁은 의미에서의 해외 이주 노동자의 송금을 remittance로 규정한다. 
의에 포함되는 경우가 있다 (Buch et al., 2002; Sørensen, 2004). 물론 해외 이주가 아닌 (국내적인) 도농간 이주에 있어서도 이주 노동자의 송금이 발생할 수는 있지만, 일반적으로 단 일 경제구조를 가지고 있는 동일지역에서 보다 그 특성과 구조가 상이한 이국간 경제지역에서 의 송금으로 인한 임금격차가 더 크게 발생한다는 전제 아래, 해외 송금은 이주 노동자가 속한 가계의 생계(livelihood)에 미치는 영향이 더 클 수밖에 없다는 사실은 부연할 필요가 없다 하 겠다.

〈표 1〉 개도국으로 유입되는 해외 송금액 (2009-2015년)

\begin{tabular}{|l|ccccccc|}
\hline & $\mathbf{2 0 0 9}$ & $\mathbf{2 0 1 0}$ & $\mathbf{2 0 1 1}$ & $\mathbf{2 0 1 2 e}$ & $\mathbf{2 0 1 3 f}$ & $\mathbf{2 0 1 4 f}$ & $\mathbf{2 0 1 5 f}$ \\
\hline \$ billions & & & & & & & \\
All developing countries & $\mathbf{3 1 6}$ & $\mathbf{3 4 1}$ & $\mathbf{3 8 1}$ & $\mathbf{4 0 6}$ & $\mathbf{4 3 8}$ & $\mathbf{4 8 2}$ & $\mathbf{5 3 4}$ \\
$\quad$ East Asia and Pacific & 85 & 95 & 106 & 114 & 123 & 136 & 152 \\
$\quad$ Europe and Central Asia & 37 & 37 & 41 & 41 & 45 & 51 & 58 \\
$\quad$ Latin America and Caribbean & 57 & 58 & 62 & 64 & 68 & $\mathbf{7 5}$ & 84 \\
Middle-East and North Africa & 34 & 41 & 43 & 47 & 50 & 53 & 56 \\
South Asia & 75 & 82 & 97 & 109 & 118 & 130 & 144 \\
Sub-Saharan Africa & 28 & 29 & 31 & 31 & 33 & 36 & 39 \\
& & & & & & & \\
LDCs (UN-classification) & 23 & 25 & 27 & 30 & 33 & 37 & 42 \\
Low-income countries & 21 & 23 & 28 & 32 & 36 & 41 & 47 \\
Middle income & 294 & 318 & 353 & 374 & 402 & 441 & 487 \\
High income & 119 & 121 & 133 & 128 & 133 & 141 & 151 \\
World & $\mathbf{4 3 5}$ & $\mathbf{4 6 2}$ & $\mathbf{5 1 3}$ & $\mathbf{5 3 4}$ & $\mathbf{5 7 0}$ & $\mathbf{6 2 3}$ & $\mathbf{6 8 5}$
\end{tabular}

$\mathrm{e}=$ 추정액; $\mathrm{f}=$ 전망액

자료출처 : Migration and Development Brief (Vol.19), Migration and Remittances Unit, World Bank.

해외 이주 노동자가 본국으로 보내는 송금은 개도국 경제에 있어 중요한 외부 재원의 원천 이다. 위의 〈표 1〉에서 보는 것과 같이 2010년 통계에 의하면 해외 이주 노동자가 본국으로 송금한 액수는 미화(U\$) 3천4백억 달러를 상회하는 것으로 나타나고 있는데, 이는 공식적으로 통계에 잡히는 수치만을 의미하기 때문에 실제 송금액은 이보다 더 클 것으로 예상 된다 (Mohapatra, 2010).

이는 2010년 전체 ODA의 3 배가 넘는 금액이며, 다음 장의 〈그림 1 〉에서 보듯 동년 전체 외 국인 직접투자(FDI)의 $60 \%$ 정도를 차지하는 수준이라고 할 수 있다 


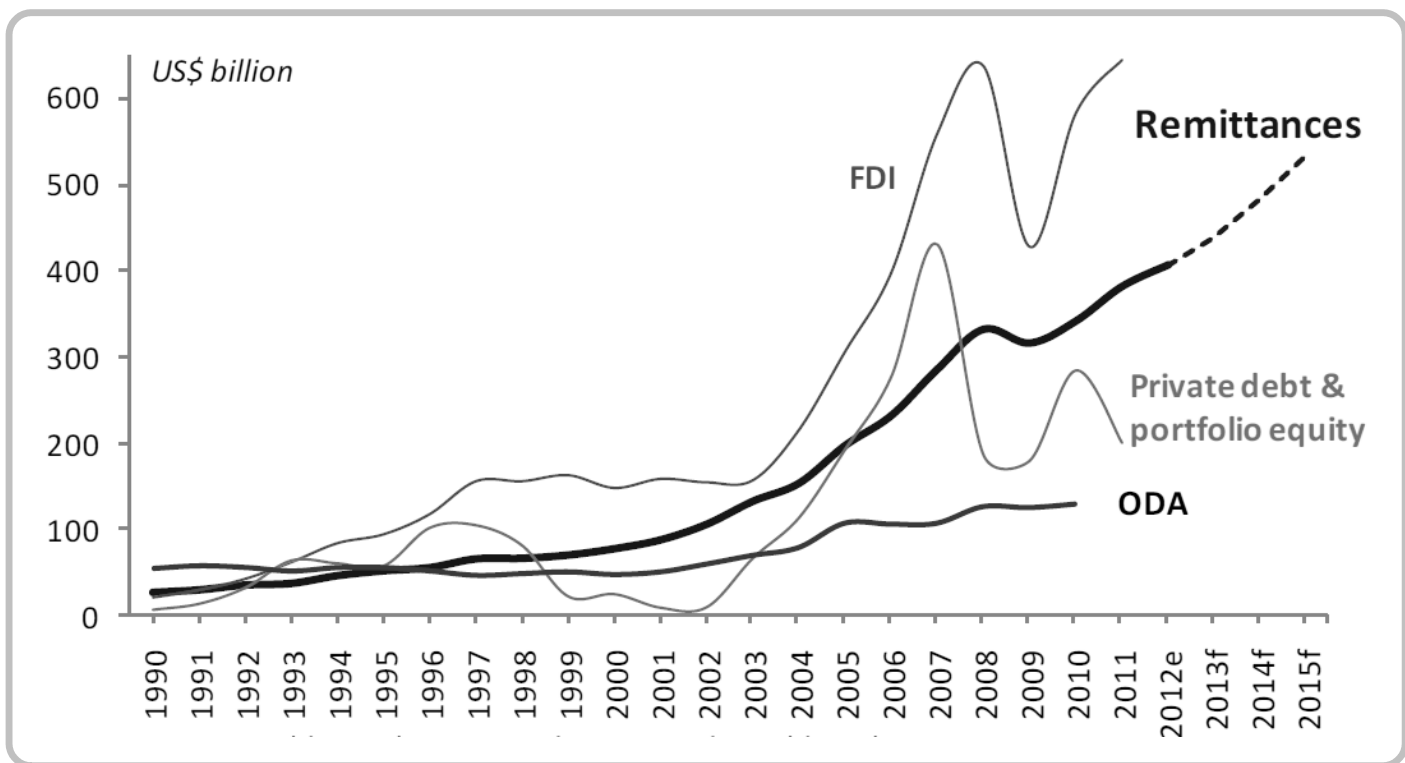

자료출처: Migration and Development Brief (Vol.19), Migration and Remittances Unit, World Bank.

다음 장의 〈그림 2〉에서 보여지 듯, 2012년 통계 예상치를 보면 송금액 기준으로는 인도 (700억 달러)와 중국(660억 달러), 그리고 필리핀과 멕시코가 각각 240 억 달러로 해외 이주 노동자 송금을 가장 많이 받고 있는 나라들로 나타나고 있으나, 경제규모(국내총생산 기준)로 보았을 때는 타지키스탄(47\%)이나 라이베리아(31\%), 키르기즈스탄(29\%)과 같이 상대적으로 $\mathrm{GDP}$ 규모가 작고 빈국인 경우에 해외 이주 노동자 송금이 차지하는 비중이 높은 것을 알 수 있다. 이는 바꿔 말하면 해외 이주 노동자 송금이 개발도상국을 전체적으로 놓고 보았을 때, 민간자본의 흐름 보다 더 균등하게 배분되고 있음을 보여 준다.

세계은행 통계자료에 의하면, 해외 이주 노동자로부터 유입되는 개도국의 외부 재원은 22 개 개도국에서 그 규모에 있어 국내총생산의 $10 \%$ 를 넘어서고 있으며, 36 개 개도국에서는 기타 외부재원의 규모 보다 더 큰 것으로 나타나고 있다. 또한 12 개 개도국에서는 해외 이주자 송금 액이 해당국의 상품수출 규모 보다 큰 것으로 집계되고 있으며, 28 개 개도국에서는 최대 단일 수출품목 보다 그 규모가 더 큰 것으로 나타나고 있다. 이러한 해외 송금액의 수치는 멕시코의 경우에 외국인 직접투자의 규모 보다 큰 것이며, 스리랑카의 경우는 최대 수출 품목 중 하나인 차(tea)의 수출 금액을 능가하는 규모이다 (Yang, 2005). 
〈그림 2〉해외 이주 노동자 송금 수신국 순위 (미화/GDP 대비 비율)

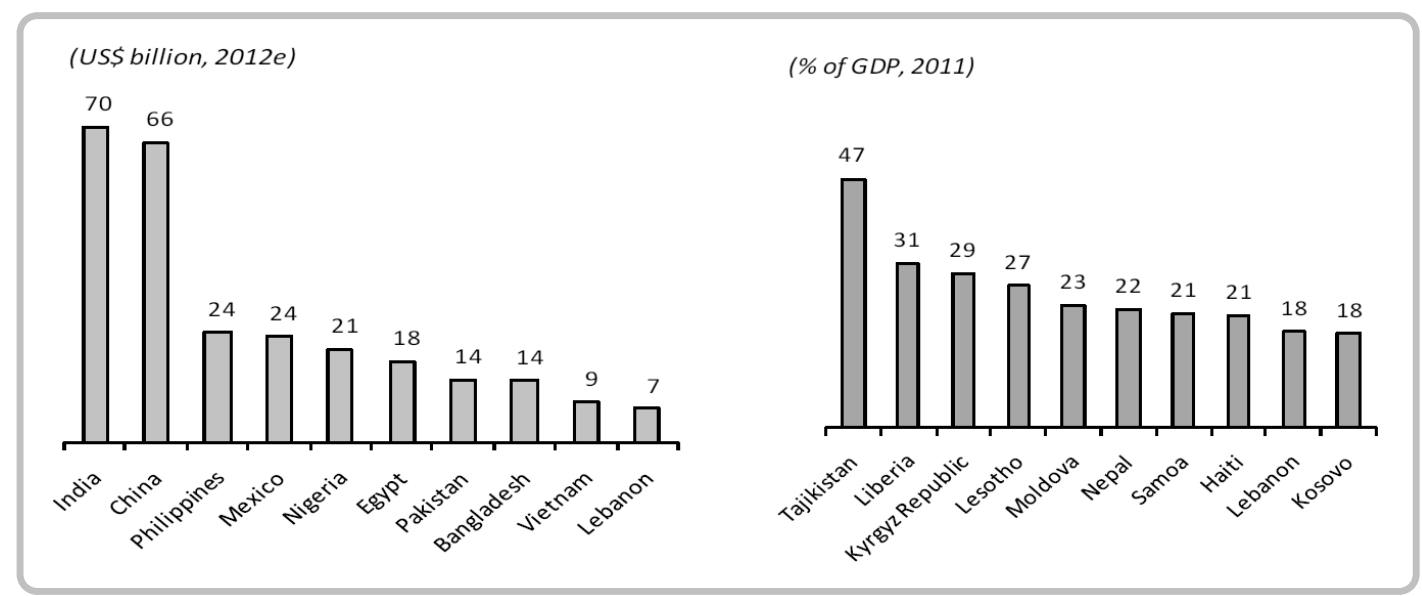

자료출처: World Bank staff calculation based on data from IMF Balance of Payments Statistics Yearbook 2011

\section{〈그림 3〉 환율 변화에 따른 격월간 이주 노동자의 송금액 변화}

(인도, 멕시코, 방글라데시, 2010-2011년)

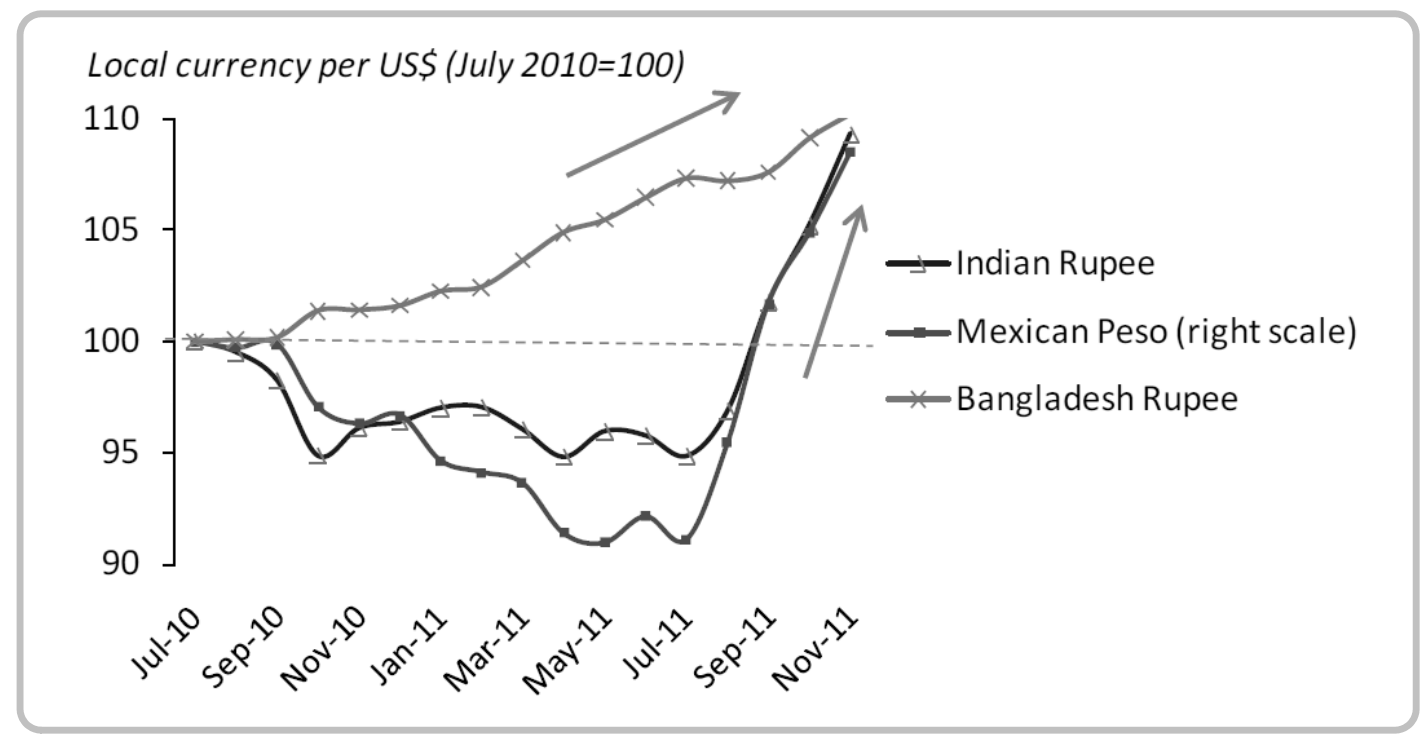

자료출처 : Migration and Development Brief (Vol.17), Migration and Remittances Unit, World Bank.

해외 이주 노동자의 송금액은 때로는 민간자본의 흐름보다 더 안정적인 경우가 많은데, 이 는 수원국의 경제사정이 악화되거나 자연재해로 피해를 입는 경우 등 위기상황이 닥쳤을 때 해외 이주 노동자의 송금액이 평소 보다 증가하는 현상에서 개발재원으로써의 그 잠재력을 보 여주는 것이라 할 수 있다(Yang, 2005). 또한 위의 〈그림 3〉에서 보는 바와 같이 해외 이주자 의 송금액은 국제 환율 변화와도 밀접한 관련이 있는데, 미국 달러화 대비 본국 통화가치가 평 
가절하 되는 경우에는 환차익을 통한 구매력 증대 측면에서 송금액이 증가하는 것을 볼 수 있 다. 이렇게 해외 이주노동은 임금격차로 인한 단순한 소득 증대에도 긍정적인 영향을 주지만, 자연재해 등 예기치 않은 외부충격이나 경제 위기상황 등의 위험에 노출 되었을 경우 가계소 득의 원천을 다변화할 수 있는 수단이며, 이주 노동자 송금은 본국의 가계에 소득의 안정성을 확보해 준다는 측면에서 그 의미가 더하다고 할 수 있겠다.

\section{3. 해외 이주 노동자 송금의 효과}

해외 이주 노동자 송금의 효과는 수원국 가계에 직접적인 소득원이 되는 것 이외에도 간접 적인 승수효과2)를 통한 빈곤감소와 웰빙(well-being)에도 영향을 주는 것으로 알려져 있다 (De et al., 2005). 국제통화기금 자료에 따르면, 국별 회귀분석에 있어 해외 이주 노동자의 송금은 빈곤감소에 통계적으로 유의미한 수치를 보여주고 있는데, 예를 들어 1 인당 해외송금 액이 $10 \%$ 증가하는 경우 평균적으로 빈곤인구의 분포가 $3.5 \%$ 정도 감소하는 것으로 나타나고 있다 (Adams et al., 2005). 또한 다른 연구결과에 따르면, 사하라 이남 아프리카 지역과 중 남미 지역에서의 해외 이주 노동자 송금의 빈곤감소 효과가 보고된 바 있는데, 개도국마다 정 책환경이 균일하지 않기 때문에 이를 일반화하기란 쉽지 않지만, 해외 이주 노동자의 송금이 경제적인 측면에서 긍정적인 역할을 하는 것만은 분명한 일이다 (Adams, 2005; IADB-MIF, 2004).

이주 노동자가 보내는 해외 송금액에 대한 분석자료를 보면 이들의 본국 송금이 몇몇 저소 득 국가에서는 인구대비 빈곤률을 상당부분 감소시키는 것으로 나타나고 있다. 예를 들어 아 프리카 대륙의 가나와 우간다, 또는 아시아 대륙의 방글라데시와 같은 나라에서는 해외 이주 노동자들의 송금에 의해 인구당 빈곤률이 $5 \sim 10 \%$ 정도 감소 추세를 보인다 (Adams, $2005 \mathrm{a}$; 2005b). 2011년 세계은행이 발표한 통계 자료에서도 이와 같은 추세를 확인할 수 있는데, 네 팔에서는 지난 10 년간 해외 이주 노동자의 송금액이 어려운 정치적, 경제적 여건 속에서도 꾸 준히 증가하여 빈곤률을 감소시키는 역할을 하였다. 물론 해외로 일자리를 찾아 이주를 떠나

2) 승수효과(multiplier effect)란 경제 현상을 설명하는 용어로, 어떤 경제 요인의 변화가 다른 경제 요인의 변화를 가져와 그 파급 효과로 인해 최종적으로는 처음 몇 배의 증가 또는 감소로 귀결되어 나타나는 최종 산출된 총효과를 말한다. 어 떤 독립 변수의 변화에 대해 다른 모든 변수가 어떤 비율로 변화하는가를 나타내는 것을 승수라고 하는데, 이를 체계적 으로 정리하여 경제 이론에 도입한 것은 영국의 경제학자 케인즈(J. M. Keynes)이다. 
는 과정에서 발생하는 기회비용 등을 고려할 때 해외 노동 이주가 단기적으로는 가계 소득증 대에 악영향을 미치는 경우도 있지만, 이러한 단기적인 영향이 상대적으로 극빈층 가계에 미 치는 영향은 크지 않은 것으로 연구된 바 있다3) (Sørensen, 2004).

임금격차로 인한 소득증대를 기대하고 해외로 이주한 노동자들은 대부분 소득의 일정부분 을 본국 가계로 송금하고 있으나, 극빈층 출신의 이주 노동자들은 이주로 인해 발생한 초기비 용을 상환해야 하는 입장이기 때문에 이주 초기에 송금을 하지 못하는 경우가 많은 반면, 중저 소득그룹 이상 상위소득 계층의 이주 노동자들은 해외송금으로 인해 본국 가계의 소득수준에 크게 기여하는 경우가 많다. 예를 들어 아래 〈그림 4>에서 보는 바와 같이 스리랑카의 국내 소 득 그룹을 10 개로 구분하였을 때, 해외 이주자 송금이 이주자가 속한 가계를 상위 소득그룹으 로 이동하게 해주는 비율은 3그룹 까지는 그 효과가 미미한 반면, 4 8그룹에서는 그 효과가 상당하여 빈곤감소에 기여하는 바가 크다고 할 수 있겠다 (De et al., 2005; World Bank, 2006).

\section{〈그림 4〉 해외 이주 노동자 송금의 소득증대 기여 효과 (스리랑카, 2006)}

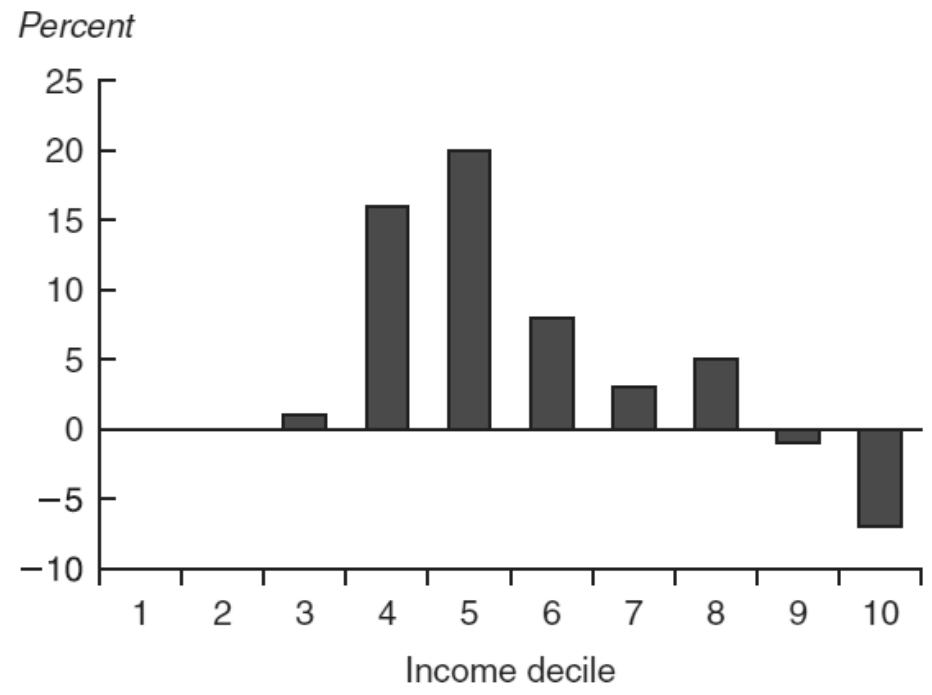

자료출처 : Global Economic Prospects 2006

3) 저소득 개도국의 극빈층의 경우, 현지에서 고용된 상태라 하도라도 임금수준이 매우 낮으며, 실업 상태에 있는 가구의 수가 많기 때문에 해외 이주를 준비하는 과정에서의 실업 상태가 가계 경제에 크게 영향을 주지는 않는 것으로 분석되었 다. 
해외 이주 노동자의 송금은 거의 모든 경우에 가계소득에 긍정적인 영향을 주어, 교육과 보 건 분야에 대한 지출을 증가시키며, 때때로 창업을 위한 투자로 이어지기도 한다. 엘살바도르 와 스리랑카에서 실시된 가계 설문조사 결과에 따르면 엘살바도르에서는 해외송금을 받는 수 원국 가계의 자녀들은 이주 노동자가 없는 가계와 비교하였을 때 상급학교 진학률이 더 높은 편이었고, 중도에 자퇴를 하는 비율이 낮았으며, 사교육비에 대한 지출이 전반적으로 더 높았 다 (Cox et al., 2003; De et al., 2005). 스리랑카에서는 해외 이주 노동자의 송금을 받는 가 계가 그렇지 않은 가계와 비교하였을 때, 자녀들의 평균체중이 더 높고 의료비 지출이 많은 것 으로 나타나 보건의료 부문에 있어서도 상당한 차이를 보였다 (De et al., 2005).

이외의 다른 연구들에서도 해외 이주 노동자의 송금은 소규모 자영업 창업과 신용도 문제를 해결해 주는 역할을 하여 지역공동체 경제에도 긍정적인 영향을 미치는 것으로 조사되었다 (Orozco, 2004; Yang, 2004). 이는 해외 이주 노동자 송금이 단기적으로는 교육과 보건의료 분야에 대한 지출을 늘려주고 투자기회를 제공해 주는 것과 더불어, 중장기적으로는 경제성장 에도 긍정적인 효과가 있는 것으로 보여지며, 특히 재무구조가 건전하지 못한 경제에서는 신 용 제약으로 인해 어려웠던 금융서비스에 대한 접근 문제를 해결하여 지역사회 경제에 전반적 으로 긍정적인 효과를 가져 오는 것으로 보고되고 있다 (Orozco, 2004). 또한 이러한 해외송 금의 효과는 건전한 정부정책을 가지고 있는 나라에서 물적자본과 인적자본에 대한 투자가 더 많이 나타난 것으로 미루어 보아, 정책의 정비가 잘 이루어져 있는 나라에서 경제성장에 더 효 과적인 것으로 분석되었다 (Ellerman, 2003).

그러나 해외 이주 노동자 송금에 대한 실증분석에서는 이주 노동자 송금의 경제성장에 대한 효과가 분명하지 않았는데, 이는 해외 송금으로 촉발된 물적, 인적자본에 대한 투자가 중장기 에 걸쳐 그 효과가 나타나기 때문인 것으로 보여지며, 계량분석 모델에 있어 해외 이주 노동자 송금과 경제성장간 상호작용이나 인과관계를 명확하게 파악하기가 어려운데서 기인한 것으로 볼 수도 있다. (World Bank, 2006). 그러나 앞서 살펴본 바와 같이 해외 이주 노동자 송금이 가계소득 증대와 그로 인한 빈곤감소 효과가 있는 것으로 보고되었다 하더라도 계량분석에서 분명한 인과관계를 규명하기가 쉽지 않기 때문에 해외 이주자 송금의 경제성장 효과를 단언하 기는 어려운 문제이다. 실제로 가계소득 증대가 투자로 전환되지 않고 소비를 진작시키는 역 할에만 머문다면 성장의 효과는 반감될 수밖에 없다고 할 수 있겠다. 


\section{4. 개발을 위한 해외 이주 노동자 송금의 역할}

개발의 관점에서 해외 이주 노동자 송금을 들여다보면, 이주 노동자를 송출하는 국가와 이 주 노동자를 영입하는 국가 모두 이주 노동자에 대한 적절한 정책을 수립하여 운영할 때 해외 송금의 개발효과를 크게 진작 시킬 수 있을 것으로 예측된다.

대부분의 개도국에서는 해외 이주 노동자 송금액을 유치하기 위해 세금혜택4)을 주는 정책 을 사용하고 있는데, 이렇게 유치한 해외 이주 노동자 송금으로 이주 노동자 조합을 결성하여 집단적인 투자를 가능하게 하는 매칭펀드(matching-fund) 등의 프로그램을 운용한다면, 이 를 소규모 지역사회 개발 프로젝트 등과 연결시켜 지역공동체를 위한 공공재 투자5)에도 활용 되어질 수 있을 것으로 보인다 (Sørensen, 2004).

이러한 긍정적인 개발효과를 이끌어 내기 위해서는 은행이나 송금대행 업체 등을 통한 공식 적인 이체 관행을 정착시키는 것이 저축증대 효과와 이를 통한 투자 기회를 확보할 수 있다는 측면에서 중요하다고 하겠다 (Adams, 2005c). 만약 해외 이주자의 송금이 공식적인 채널을 통해 이루어지지 않고 인편을 통한 현금전달 등의 방식으로 이루어진다면, 은행계좌를 통한 송금에 비해 상대적으로 저축효과가 떨어질 것이라는 것은 쉽게 예상할 수 있다. 개도국에 있 는 대부분의 빈곤층 가정에서는 금융서비스 제약으로 인해 해외 이주 노동자의 송금이 금융권 과의 접촉을 유지시켜주는 유일한 매개가 되는 상황이 많기 때문에, 개도국 정부와 금융기관 들은 해외 이주 노동자 송금을 유치하기 위한 유인책을 시행할 필요가 있다 (Aite Group, 2005).

해외 이주 노동자 송금은 거시경제적인 측면에서도 국가 신용도 제고에 기여하여 국제자본 시장에 대한 접근성을 높여준다. 미국 달러화와 같은 경화(hard currency)의 송금은 공식적인 경로를 통해 유입될 때 국가신용도에 미치는 영향은 상당하다고 할 수 있다 (Ratha, 2004). 더불어 이러한 해외 이주자 송금은 개도국 금융권에 대한 일종의 보증 기능을 담당할 수 있기

4) 일부 개도국 정부에서는 해외 이주자 송금액에 대한 면세혜택을 주지 않고 있는데, 이는 결과적으로 송금비용을 가중시 키는 것과 비슷한 효과를 유발하여 빈곤층 가계에 도움을 주지 못하는 결과를 초래한다. 또한 해외 송금액에 대한 세금 부과는 불법송금에 대한 유인을 제공하여 이로 인한 지하경제 양성화에 기여하는 부분이 있기 때문에 대부분의 개도국 에서는 해외 송금에 대해 면세와 같은 인센티브를 제공하고 있다.

5) 해외 이주자 송금은 기본적으로 민간재원의 성격을 가지고 있어 잠재적으로 가지고 있는 개발효과에도 불구하고 이를 정 부의 공공투자나 해외에서 유입되는 공적개발원조(ODA)를 대체할 수 있는 수단으로 기대하는 것은 현실적이지 않다. 
때문에 개도국 정부나 상업은행들이 자본시장에서 더 좋은 조건으로 채권을 발행할 수 있게 해주는 등 국가경제에 미치는 영향도 상당하다. 실제로 브라질, 터키, 엘살바도르 등과 같은 개발도상국들의 금융기관은 향후 해외 이주 노동자 송금을 담보로 국제 자본시장에서 장기, 저리의 파이낸싱이 가능해져 이를 활용한 투자 자금을 지속적으로 유치하고 있으며 (World Bank, 2011), 엘살바도르의 경우에는 이주 노동자 송금액을 기반으로 증권사들이 국가 신용 도 보다 상위의 투자적격 등급을 부여 받아 외국인 투자를 유치하고 있다. 그 결과 채권을 발 행하는 기관에서는 만기 구조가 장기인 저금리 채권발행을 통해 자본을 조달할 수 있게 되었 을 뿐만 아니라, 신용도 제고를 통해 향후 자본시장에 접근할 수 있는 비용을 줄이는 효과를 가져 오고 있다 (Cox et al., 2003; Ratha, 2004).

\section{5. 소결}

교통, 통신의 발달 및 세계화 현상과 맞물려 ‘국제이주의 시대’라고 불리울 만큼 국제 노동 이주가 일반화된 오늘날, 개도국에서 선진국으로의 노동이주와 이로 인한 해외 이주 노동자의 송금은 국제사회에 개도국 개발과 저소득층의 빈곤감소 논의에 대한 주요한 화두를 던져 주고 있다. 많은 국제기구들이 이미 국제이주노동에 대한 이슈들을 제기하고 있고, 개도국 정부들 도 해외 이주 노동자 송금을 외화유치 전략의 핵심으로 인식하면서 자국의 경제사회 문제 해 결을 위한 유용한 수단으로 해외 이주 노동자 송금 문제를 바라보고 있다. 앞서 살펴본 바와 같이 해외 이주 노동자 송금이 가지고 있는 긍정적인 효과는 개도국 정부와 금융기관 및 빈곤 층 가계에 걸쳐 광범위하게 나타나고 있는 상황이다.

물론, 해외 이주 노동자 송금이 거시경제적 측면에서 자국의 통화가치를 상승시켜 수출에 부정적인 효과를 가져다준다든지 (World Bank, 2006), 이주 노동자 송금의 지역개발 효과에 기대어 정부가 공공재에 대한 투자를 미루는 현상 등에 대한 비판적인 시각도 존재하는 것이 사실이다 (Ellerman, 2003; Orozco, 2004). 또한 현상적으로는 이해할 수 있는 해외 이주 노 동자 송금의 긍정적인 효과가 실증적으로 입증되기 어렵다는 지적과 함께 정책적 기반이 취약 하고 빈곤국일수록 대규모 해외 이주 노동자 송금에 의지하려는 경향이 있어 장기적인 경제구 조의 건전성을 훼손한다는 비판 역시 종종 있어 왔다 (IOM, 2003; Levitt et al., 2004).

하지만, 경제적 위기 상황에 직면했을 때 해외 이주 노동자 송금이 더 증가하는 경향을 보 
인다거나, 이주 노동자 송금이 교육 기회와 보건의료 부문에 대한 저소득층의 지출을 늘려 중 장기적으로 빈곤 감소에 긍정적인 영향을 주는 것, 그리고 가계 및 국가 신용도 제고와 이를 통한 투자 기회의 확보를 통해 경제성장을 이끌어 낼 수 있는 잠재력을 가지고 있는 부분 등은 누구도 부인하기 어려운 해외 이주자 송금의 긍정적인 영향일 것이다. 물론 일부 소득계층에 서 이주 노동자의 송금이 생산적인 활동에 쓰이지 않고 대부분 과시적인 소비지출에 쓰인다는 비판에 대해서는 이주 노동자 송금이 더 건설적인 방향으로 활용되도록 이끌어 주는 개도국 정부의 정책이 시급하다고 하겠다 (Maeng, 2011). 아래에서는 지금까지의 논의를 바탕으로 해외 이주 노동자 송금의 개발효과 진작을 위한 현실적인 정책적 대안을 간략하게 제시 하려 고 한다.

1) 본국 지역사회 개발을 위한 'Home Town Association'의 결성을 정책적으로 검토할 필 요가 있으며, 지역사회 모두에게 혜택이 돌아갈 수 있는 소규모의 개발 프로젝트 사업을 지역 정부가 주민들과 협의하여 시범적으로 시행해 볼 필요가 있다.

2) 이주 노동자들이 해외 송금 시 계좌이체 등과 같은 공식적인 채널을 이용하고, 이를 통 해 금융기관의 신용서비스와 송금 누적액에 대한 인센티브를 받을 수 있는 제도적 장치 를 마련해야 한다.

3) 금융기관들은 해외송금 유치를 위해 보다 좋은 조건의 금융상품을 개발하여 이를 이용하 는 소비자들이 송금액의 일부를 저축할 수 있는 유인책을 제시할 수 있어야 하며, 해외 이주자에게 송금을 받는 가계들이 네트워크를 형성, 이를 통해 지역사회를 개발할 수 있 는 기회를 모색해야 한다.

사실 위에 제시된 세 가지 정책방안은 새로운 대안이 아니라, 이미 몇몇 개도국 지역사회에 서 시행되고 있는 성공사례를 제시한 것이다. 하지만 이러한 정책방안을 실제로 시행하고 있 는 사례는 찾아보기가 쉽지 않을 뿐만 아니라 해외 이주 노동자를 송출한 개도국 정부나 지역 사회, 개발 실무자들에게 이주 노동자 송금의 경제적 효과가 아직 깊이 있게 뿌리내리지 않은 것으로 여겨져 성공사례 구축을 위한 효과적인 방안을 상기시키는 차원에서 제시하였다.

최근 국제 이주노동을 둘러싼 다양하고 복잡한 논의들은 이주노동 현상에 대한 보다 분석적 이고 현실적인 정책 대안을 요구하고 있다. 본고에서는 전반적으로 해외 이주 노동자 송금의 긍정적인 측면을 부각하려 했지만, 실상은 해외이주 자체가 현지 보다 높은 소득을 항상 보장 
해주는 것도 아니며, 많은 경우에 있어 해외 이주노동은 개도국에 거주하는 빈곤층이 소득증 대를 위한 마땅한 대안이 존재하지 않을 때 최선이 아닌 최후의 수단(last resort)으로 선택하 는 경제활동이라는 점에서 해외 이주노동과 이주 노동자 송금이 가져다 줄 수 있는 기대효과 에 대한 다소 과장된 전망은 주의할 필요가 있다. 다만, 국제 이주노동 문제에 관여하고 있는 이해관계자들이 이주노동 정책과 이주자 송금을 활용하는 방안을 더 진지하게 고민하고, 이주 노동자들이 더 많은 혜택을 누릴 수 있도록 긍정적인 효과를 가져 오는 정책을 마련할 필요가 있다는 점은 다시 한 번 상기할 필요가 있다 하겠다. 


\section{참고문헌}

Adams, Richard. (2005a). "International Remittances and the Household: Analysis and Review of Global Evidence." Paper presented at the Plenary Session of the African Economic Research Consortium, May 29, Nairobi.

. (2005b). "Remittances and Poverty in Ghana". World Bank, Washington, DC. (2005c). "Remittances, Household Expenditure and Investment in Guatemala. In International Migration, Remittances, and the Brain Drain, ed. Caglar Ozden and Maurice Schiff. Washington, DC : World Bank.

Adams, Richard, and John Page. (2005). "Do International Migration and Remittances Reduce Poverty in Developing Countries?” World Development 33(10) : 1645-69.

Aite Group. (2005). Consumer Money Transfers : Powering Global Remittances. Boston, MA : Aite Group, LLC.

Buch, C.M., Kuckulenz, A. and Le Manchec, M. (2002). Worker Remittances and Capital Flows. Working Paper, Kiel Institute of World Economics.

Cox Edwards, Alejandro, and Manuelita Ureta. (2003). "International Migration, Remittances, and Schooling : Evidence from El Salvador." Journal of Development Economics 72(2) : 429-61.

De, Prabal, and Dilip Ratha. (2005). "Remittance Income and Household Welfare : Evidence from Sri Lanka Integrated Household Survey”. Development Research Group, World Bank, Washington, DC.

Ellerman, David. (2003). “Policy Research on Migration and Development." World Bank Policy Research Working Paper 3117. August.

Goldring, L. (2004). Family and Collective Remittances to Mexico. A Multi-dimensional Typology. Development and Change 35(4):799-840.

IADB-MIF (Inter-American Development Bank, Multilateral Investment Fund). (2004). "Sending Money Home : Remittance to Latin America and the Caribbean." Washington, DC.

Levitt, P. \& N. N. Sørensen. (2004). The Transnational Turn in Migration Studies. Global Migration Perspectives, No. 6:2-13.

Maeng, J. (2011). "The Implications of Labour Migration on Poverty and Well-being for the Households in Rural Thailand”. PhD Thesis. University of Manchester. 
Mohapatra, S. (2010). Outlook for Remittance Flows 2011-12 : Migration and Development Brief, Vol.13. World Bank, Washington, DC.

Ratha, D. (2003). Worker Remittances: An Important and Stable Source of External Development Finance. Global Development Finance 2003. Washington, DC : The World Bank.

Ratha, D. (2004). Recent Trends in International Remittance Flows. Paper presented at the Technology on Remittances Workshop, San Francisco, CA.

International Organization for Migration (IOM). (2003). World Migration 2003 : Managing Migration - Challenges and Responses for People on the Move. Geneva, Switzerland: International Organization for Migration. National Money Transmitters Association, data on monthly flows, New Jersey, 2005.

Orozco, M. (2004), International Financial Flows and Worker Remittances : A best practices report. Report commissioned by the Population and Mortality division of the UN.

Sørensen, N.N. (2004). Migrant Transfers as a Development Tool. DIIS Working Paper 16.

World Bank. (2006). Global Economic Prospects 2006 : Economic Implications of Remittances and Migration. Washington, DC.

World Bank. (2011). Migration and Remittances Factbook 2011. Washington, DC.

Yang, Dean. (2004). "International Migration, Human Capital, and Entrepreneurship : Evidence from Philippine Migrant's Exchange Rate Shocks." Research Program on International Migration and Development. DECRG. Policy Research Working Paper 3578. World Bank.

(2005). "Coping with Disaster: The Impact of Hurricanes on International Financial Flows, 1970-2001.” Gerald R. Ford School of Public Policy, University of Michigan. 